\title{
O Impacto dos Determinantes da Oferta de Açúcar e Álcool no Brasil no Período 1995 A 20091
}

\author{
Gustavo Bertotti², Angélica Massuquetti ${ }^{2}$, Marcos Tadeu Caputi Lelis ${ }^{2}$ \\ 'Esta pesquisa recebeu o apoio da Capes \\ Universidade do Vale do Rio dos Sinos
}

\section{Resumo}

Este artigo tem como objetivo mensurar o impacto dos determinantes da oferta de açúcar e álcool no Brasil com o intuito de captar a intensidade e a duração que as oscilações de preços e de produções transmitem para o mercado brasileiro. O modelo econométrico proposto para o presente estudo consiste no método de vetor auto regressivo com mecanismo de correção de erro (VEC), com base em séries temporais trimestrais compreendidas entre o período de 1995 a 2009. Posteriormente, analisou-se, atráves dos testes de causalidade de Granger e funções de impulso resposta (FIR), a precedência entre as variáveis compreendidas nos modelos, bem como o impulso que uma variável exerce sobre as demais. Por fim, com base nos testes apresentados, chegou-se à conclusão que o modelo B com quatro defasagens apresentou os resultados mais coerentes e conclusivos em relação ao embasamento teórico e à dinâmica do setor. Dentre os principais resultados, fica evidenciada a relação positiva do açúcar e do álcool em relação à determinação de suas ofertas, no sentido de que o aumento da oferta de um produto gere no mesmo sentido a expansão do outro. Adicionalmente, os comportamentos das variáveis de preços, em parte, apresentaram resultados condizentes com a realidade do setor e na maioria dos impulsos corresponderam com os sinais esperados. As exportações de açúcar e taxa de câmbio Impactam positivamente na renda recebida pelo produtor e inferem positivamente para a expansão da oferta brasileira de açúcar.

Palavras Chave: Oferta brasileira de açúcar e álcool; Setor sucroalcooleiro; Mecanismo de correção de erros (VEC).

\begin{abstract}
This study has the objective to measure the impact of the determinants for the supply of sugar and alcohol in Brazil, with the intention to capture the duration of the osclillations of prices and production influences to the Brazilian market. The econometric model proposed for the following study consists of a vector auto-regressive model with an error correction mechanism based on quarterly temporal series within the period of 1995 to 2009. Afterwards, it was analyzed through Granger causality tests and the impulse response function (IRF) the precedence among the variables comprehended in the models, as well as the impulse that a variable applies over the others. At last based on the tests presented it has got to the conclusion that the model B with four lags, showed the most coherent and conclusive results concerning the theoretical support and the dynamics of the sector. Among the main results it is evident the positive relationship of sugar and ethanol concerning the determination of its offers, at the sense that the increase one product generates, at the same point, the expansion of the other. In addition the behaviors of the variables of prices, in part presented results in agreement to the expected signals. The sugar exports and exchange rate impact positively in the income received by the producer and infer positively for the expansion of the Brazilian sugar offer.
\end{abstract}

Keywords: Brazilian offer of sugar and alcohol; Sugarcane sector; Error correction mechanism (VEC). 


\section{INTRODUÇÃO}

O complexo agroindustrial canavieiro constitui-se na mais antiga atividade econômica do Brasil. O cultivo da cana e a fabricação do açúcar eram atividades econômicas tradicionais no Brasil colonial, sendo esse o primeiro produto básico de exportação a partir do final do século XVI (SUZIGAN, 2000). A região Nordeste do país, mais especificadamente a Zona da Mata, foi a principal produtora de açúcar durante o período colonial, perdendo sua hegemonia para a região Centro-Sul somente em meados do século $\mathrm{XX}$. Dentre os principais autores que descrevem a cultura canavieira no Brasil, destacam-se Prado Junior (1981), Suzigan (2000), Baer (2002), Furtado (2003) e Vian (2003).

O complexo canavieiro nacional passou por diversas fases de expansão da produção, que possibilitaram uma contínua elevação da capacidade produtiva e um aumento das áreas ocupadas para o cultivo da cana. Segundo Furtado (2003), após a Independência do país, o Estado adotou uma política mais liberal, deixando a comercialização do setor sob a responsabilidade da iniciativa privada. Este fato gerou incentivos pontuais para as exportações e a modernização tecnológica (ALVES, 2002).

A partir da década de 1930, o setor sucroalcooleiro enfrentou diversas oscilações de preços decorrentes das incertezas do mercado internacional. Este período também foi marcado pelo aumento da importância da região Centro-Sul, especialmente com a concentração da produção no estado de São Paulo após a criação do Instituto do Açúcar e do Álcool (IAA), em 1933. O IAA teve como objetivo resolver o problema da superprodução da indústria canavieira através do planejamento e do controle da produção, adequando-os às necessidades do consumo e favorecendo os investimentos tecnológicos. No final da década de 1940, a região Centro-Sul já produzia mais açúcar de usina que a região Nordeste, fato este que se deu devido à autossuficiência da indústria paulista. Ressalta-se, ainda, que o protecionismo governamental conteve parcialmente as crises no setor sucroalcooleiro, já que as políticas adotadas pretendiam garantir os níveis adequados de preços para os produtores competirem no mercado internacional. Todavia, as medidas econômicas consistiam, principalmente, em políticas cambiais (desvalorização cambial) e políticas de incentivos fiscais (ALVES, 2002).

Após a década de 1940, a agroindústria canavieira passou por diversas inversões políticas decorrentes do deslocamento da produção açucareira da região Nordeste para o Centro-Sul do país, o que podem ser em parte explicadas pela erradicação dos cafezais no estado São Paulo. $\mathrm{Na}$ década de 1960, alguns fatores conjunturais alteraram as perspectivas do setor, dentre eles destaca-se a Revolução Cubana, que exclui Cuba do mercado preferencial estadunidense, abrindo mercado para os produtores nordestinos, que até então eram dependentes da demanda do Centro-Sul e da demanda externa. Costa (2003) destaca que apesar das intensas flutuações nas ofertas e nos preços mundiais no curto prazo, os excedentes nordestinos não seriam suficientes para atender às crescentes demandas do mercado açucareiro.

No início da década de 1970, verificou-se um grande fomento estatal às exportações, assim como programas de melhoria de produtividade e de racionalização da produção. Segundo Baer (2002), a partir do primeiro choque do petróleo em 1973-1974, o Brasil passou a reagir através da continuidade de programas destinados à substituição das importações, que possibilitaram maiores investimentos em projetos de infraestrutura com intuito de facilitar a diversificação das exportações. Neste contexto, vários programas foram criados, dentre eles o Programa de Racionalização da Agroindústria Açucareira, no ano de 1971, que foi substituído pelo Programa de Apoio à Agroindústria Açucareira, no ano de 1973, e, em seguida, pelo Programa Nacional do Álcool (Proálcool), em novembro de 1975. Conforme Furtado (2000), o Proálcool tornou-se o maior projeto de energia alternativa do mundo, elevando a participação do álcool anidro e hidratado na área de combustíveis líquidos, que era de $1,2 \%$, em 1978 , para $8,1 \%$, em 1984. A partir de 1985, o controle da inflação passou a ser um dos principais objetivos do governo brasileiro, o qual estabeleceu a rigidez dos preços dos combustíveis e do açúcar como critério de contenção dos preços (NOGUEIRA, 2011).

Nos primeiros anos da década de 1990, deu-se início ao processo de desregulamentação dos produtos do setor sucroalcooleiro por meio da liberação do preço do açúcar, que se estendeu para o preço do álcool anidro e, posteriormente, para os preços da cana de açúcar e do álcool hidratado. Neste contexto, os preços do setor sucroalcooleiro passaram a ser determinados de acordo com as regras de livre mercado e, desde então, o setor tem passado por profundas transformações em um período relativamente curto de tempo (ALVES, 2002).

O setor sucroalcooleiro, entre as safras de 1997/1998 e 1998/1999, passou por uma crise decorrente da queda dos preços do açúcar no mer- 
cado internacional, resultando em uma redução nas exportações e um acúmulo nos estoques de álcool, atingindo o montante de 1,8 bilhões de litros, na safra de 1997/1998. Logo, os excedentes de produção do açúcar e do álcool foram absorvidos no início do ano 2000, devido à retomada no setor externo, o que proporcionou um crescimento das exportações brasileiras na ordem de US $\$ 2$ bilhões, no ano de 2002 (VIAN, 2003).

A agroindústria canavieira brasileira possui grande importância no contexto econômico, ocupando uma posição de destaque no comércio internacional ao produzir, em escala industrial, tanto o açúcar quanto o álcool e, mais recentemente, a energia elétrica co-gerada do bagaço da cana. Segundo dados da UNICA (2010), na safra de 2008/2009, o Brasil produziu, aproximadamente, 569 milhões de toneladas de cana de açúcar, movimentando, na economia, aproximadamente, R\$ 51 bilhões e gerando mais de 4,5 milhões de empregos diretos e indiretos.

Com base nesse cenário e considerando a importância da produção do setor sucroalcooleiro na economia, bem como sua inserção no mercado internacional, justifica-se o estudo da dinâmica da produção brasileira do açúcar e do álcool. Adicionalmente, o álcool pode ser visto como fonte de energia renovável, já que, em parte, pode substituir uma fração futura da energia gerada por combustíveis fósseis. Destaca-se, ainda, que os demais estudos que abordam o tema tendem a analisar a inter-relação de preços entre as diferentes regiões do mercado interno brasileiro e não possuem um enfoque sobre a inter-relação dos produtos do setor brasileiro com o mercado externo, com base na ótica da oferta. Além disso, não mensuram os impactos de preços e proxies de lucratividade, os quais se tornaram os principais problemas de pesquisa.

O objetivo geral deste artigo, portanto, é mensurar o impacto dos determinantes da oferta de açúcar e álcool no Brasil, no período 19952009 , com intuito de captar a intensidade e a duração que as oscilações de preços e de produções transmitem para o mercado. Ademais, busca-se analisar a relação de outras variáveis que podem impactar o setor, tais como a taxa de câmbio e o preço da gasolina. Em relação ao mercado internacional, busca-se analisar o mercado exportador brasileiro e sua influência sobre a formação dos preços internacionais do açúcar, pois, atualmente, o Brasil caracteriza-se como um dos principais produtores mundiais.

Nesse sentido, além da parte introdutória, o presente artigo está estruturado em mais quatro seções, sendo que a segunda refere-se aos estudos empíricos sobre os determinantes da oferta de açúcar e álcool. Na terceira seção, são definidas as variáveis, o modelo econométrico, bem como se aplicam os testes de especificações, os quais passam a validar estatisticamente o melhor modelo. Já em relação à quarta seção, são apresentados os resultados e discussões. Por fim, na quinta seção apresentam-se as considerações finais e sugestões de estudos futuros.

\section{ESTUDOS EMPIRÍCOS SOBRE OS DE- TERMINANTES DA OFERTA DE AÇÚCAR E ÁLCOOL}

Nesta seção, destacam-se alguns estudos relacionados à comercialização dos produtos do setor sucroalcooleiro, como Alves (2002), que analisou as inter-relações entre os níveis de mercado dos principais produtos do setor sucroalcooleiro do estado de São Paulo no período 1998 a 2002. A partir de uma modelagem econométrica com base nos testes de Dickey-Fuller Aumentado, Johansen e método de Auto-Regressão Vetorial com Mecanismo de Correção de Erro (VEC), o autor buscou determinar o grau de intensidade da formação e do efeito da transmissão de preços relacionados à comercialização do açúcar e do álcool no estado de São Paulo. Os resultados indicaram relações significativas entre os preços do açúcar cristal no mercado interno e o recebido pelas exportações, bem como entre os preços do açúcar cristal empacotado ao produtor e ao varejo. Em relação aos impactos de choques de uma variável sobre as demais, o autor destacou que o preço do álcool anidro impacta positivamente sobre os preços do açúcar cristal industrial e do cristal exportado somente após o quarto período. Os choques no preço do açúcar cristal causam impacto positivo nos preços do álcool anidro e do açúcar cristal com um período de defasagem. Os choques no preço do açúcar cristal empacotados ao produtor têm influência sobre os preços dos açúcares cristal industrial, cristal exportado e cristal empacotado no varejo. Por fim, os choques nos preços do açúcar cristal exportado não causam impacto nos preços do mercado interno.

Com o intuito de analisar a oferta e a demanda de açúcar no estado de São Paulo, no período de 1995 a 2000, Caruso (2002) buscou estimar, através de um sistema de equações simultâneas, as elasticidades de preço da oferta, renda e demanda do setor açucareiro. Os resultados do modelo simultâneo de oferta e demanda de açúcar apontaram que mesmo considerando a endoge- 
neidade da variável preço do açúcar com base no Teste de Especificação de Hausman, os mesmos não foram satisfatórios. Em relação à estimação específica de uma equação de demanda de açúcar para o estado de São Paulo, a autora considerou a demanda como função direta do preço do açúcar cristal $(-0,47 \%)$ e da renda do consumidor $(0,99 \%)$. Os resultados encontrados foram satisfatórios e indicaram que a demanda de açúcar no mercado brasileiro é inelástica a preço, ou seja, alterações no preço do açúcar possuem uma relação inversa menos proporcional que na demanda. Todavia, a autora concluiu que o açúcar caracteriza-se como um bem de necessidade básica que não sofre alterações de demanda decorrente de variações de preços. Da mesma forma, a demanda de açúcar é inelástica a alterações de renda no estado de São Paulo.

Marjotta-Maistro (2002) estimou, a partir dos métodos de Mínimos Quadrados em Dois Estágios e de Mínimos Quadrados Ordinários, os efeitos das mudanças na oferta e na demanda dos agentes relacionados ao mercado de combustíveis. A autora buscou captar os ajustes nos mercados de álcool e gasolina pós-desregulamentação do setor sucroalcooleiro, no período 1995 a 2000. Para a estimação, a autora partiu da definição de dois modelos relacionados a preço e à quantidade. $\mathrm{O}$ primeiro modelo foi composto por oito equações, sendo que os principais resultados foram que os ajustes via preços foram pouco eficazes para influenciar a oferta de combustíveis. O segundo modelo foi composto por cinco equações e os principais resultados foram que o governo tendia a absorver os choques externos de preços dos combustíveis, não repassando imediatamente os mesmos para o varejo e beneficiando de certa forma o consumidor final.

Alves e Bacchi (2004) estimaram uma função de exportação do açúcar brasileiro para o período de outubro de 1995 a dezembro de 2002. Através da metodologia de Auto Regressão Vetorial (VAR), os autores concluíram que a desvalorização cambial, o preço do açúcar no mercado internacional e a renda doméstica impactaram positivamente na determinação e no crescimento das exportações brasileiras.

Silveira (2004) analisou as relações entre os preços do açúcar no mercado doméstico e internacional por meio do uso de séries temporais no período 1998 a 2003. As elasticidades obtidas nas funções de transmissão de preços indicaram que os valores passados das cotações da Csce/Nybot eram referência para a formação do preço no mercado doméstico. Entre os principais resultados, o autor destacou que a produção açucareira no Brasil determina de forma significativa os preços no mercado internacional, o que em parte pode ser explicado pela competitividade das exportações brasileiras.

Colla et al. (2007) analisaram a relação da marca, do preço e do consumo do açúcar em Cascavel, no Paraná, entre o período de janeiro a julho de 2006. A metodologia usada partiu de um teste não-paramétrico através da correlação de Kendall e de Spearman, possibilitando aos autores identificar os principais fatores que influenciam o comportamento da compra do produto, além de constatarem que a fidelização da marca é pouco expressiva e que o consumidor privilegia sempre o menor preço.

Com o objetivo específico de analisar a estrutura brasileira de custos das usinas de açúcar e álcool da região Centro-Sul, no período 2002 a 2006, Albanez et al. (2008), por meio de um modelo empírico-analítico fundamentado nas metodologias de contabilidade de custos, concluíram que parte dos custos e das despesas operacionais das usinas tem comportamento variável, o que torna um fator positivo para o setor ao diminuir o risco operacional da atividade. Os autores ressaltaram também que os custos fixos são menos representativos para as usinas, já que eles ocorrerão independentemente das quantidades produzidas.

Martins et al. (2008), com base nos indicadores de desempenho, eficiência e capacitação, analisaram a competitividade do açúcar brasileiro no mercado internacional no período de 1990 a 2004. Os resultados apresentados pelos autores evidenciam que o açúcar brasileiro é altamente competitivo no comércio internacional, com tendência de crescimento no longo prazo devido aos avanços tecnológicos empregado nos processos produtivos e ao aumento da taxa geométrica de crescimento nos últimos anos.

Cunha et al. (2008) investigaram os efeitos da implantação do Plano Real no comportamento de longo prazo dos preços da cana de açúcar, praticados nos estados de São Paulo e do Paraná, no período de 1990 a 2005. Através dos testes de raiz unitária e de co-integração na presença de quebra estrutural (regime shift), o autores concluíram que os preços recebidos da cana de açúcar nos estados de São Paulo e do Paraná apresentam relação de longo prazo e os mercados são integrados mesmo com o regime shift.

Para analisar a sazonalidade dos preços da cana de açúcar no estado do Paraná no período de 2001 a 2007, Shikida e Margarido (2009), através do método econométrico da decomposição X-12, 
concluíram que a cana de açúcar paranaense apresenta poucas oscilações em seus preços devido às mesmas serem mais relacionadas aos períodos de comercialização do que em função de sua safra ou entressafra. Os autores ressaltaram que os preços da cana são fortemente influenciados pelos produtos finais (álcool e açúcar) e pela qualidade da matéria prima.

Alves e Lima (2010) analisaram a transmissão de preços entre os mercados de açúcar espacialmente separados no Brasil entre o período de maio de 2003 a dezembro de 2008. Com base na fundamentação teórica de integração de mercados, lei do preço único e arbitragem espacial, os resultados dos testes mostraram que os estados de Alagoas e de Pernambuco e as regiões de Araçatuba e de Ribeirão Preto (São Paulo), Maringá (Paraná) e Triângulo Mineiro (Minas Gerais) fazem parte do mesmo mercado econômico de açúcar no Brasil. Os autores ressaltaram, com base nos testes de co-integração de Johansen, que os mercados de Araçatuba e de Ribeirão Preto apresentaram maior grau de integração em relação à transmissão de preços.

Em relação ao mercado de etanol, Bittencourt e Fontes (2010) analisaram a competitividade das exportações brasileiras de etanol no período de 1994 a 1997. Através do método de Indice de Vantagem Comparativa Revelada de Balassa e de Lafay, taxa de cobertura e indicador de desempenho, os autores concluíram que os países que competem diretamente com o Brasil na exportação de etanol não possuem vantagem comparativa em relação ao mercado brasileiro, já que os mesmos estão focados nas suas crescentes demandas domésticas de etanol.

No estudo de Triches et al. (2010), o objetivo principal foi analisar o desempenho das exportações brasileiras de açúcar no período 1995 a 2008 e as restrições da União Europeia (UE). Dentre os resultados, os autores destacaram que o açúcar é um dos produtos mais afetados pelas medidas protecionistas e que o Brasil, a partir do ano de 2002, passou a buscar apoio da Organização Mundial de Comércio (OMC) para melhorar a competitividade no mercado internacional.

Com o intuito de analisar a demanda de etanol e de gasolina no Brasil no período de 2001 a 2009, Souza (2010) estimou as elasticidades renda e preço do consumo dos principais combustíveis para veículos leves através de uma base de dados em painel com periodicidade mensal. Dentre os resultados apresentados, o autor ressaltou que nos estados com preço relativo etanol-gasolina mais elevado, ou seja, acima de $75 \%$, a renda tende a ser menor e com demanda mais elástica. $\mathrm{O}$ autor concluiu, ainda, que o crescimento da produção de veículos flex-fuel aumenta o efeito substituição entre os combustíveis, o que de certa forma acarreta em uma maior sensibilidade no preço para os consumidores.

Tomasetto (2010) analisou a transmissão de preços no mercado de cana de açúcar entre os estados de São Paulo e do Paraná, no período de janeiro de 1995 a fevereiro de 2009. Com base nos modelos Auto Regressivos Integrados de Médias Móveis (ARIMAs), co-integração de Engle-Granger e Modelo de Correção de Erros (MCE), houve indicação de que as elasticidades de preços de curto e longo prazo possuem características inelásticas. Os resultados dos modelos de função de transferência indicaram que choques não antecipados no preço da cana de açúcar em São Paulo são transmitidos na intensidade de $41,19 \%$ para os preços da cana de açúcar no estado do Paraná no curto prazo. Já no longo prazo, os choques não antecipados no preço da cana do estado de São Paulo são transmitidos na ordem de $99,84 \%$ para o mercado paranaense.

A próxima seção apresenta a metodologia proposta, as variáveis e as fontes dos dados utilizados e a definição do modelo econométrico.

\section{MATERIAL E MÉTODOS}

\section{I METODOLOGIA}

Para captar a dinâmica do setor, busca-se, através da modelagem econométrica de vetor auto regressivo com mecanismo de correção de erros (VEC), estimar modelos multivariados de forma simultânea que permitam avaliar os efeitos de uma variável em relação às demais. Em seguida, utilizam-se as funções impulso resposta (FIR) e os testes de causalidade de Granger. De acordo com Tomasetto (2010), o VEC admite a ligação entre os aspectos relacionados às oscilações de curto e longo prazo, indicando que o modelo propõe uma estabilidade de equilíbrio entre os regimes. Já para Banerje et al. (1993), os mecanismos de correção de erro apresentam uma forma de modelagem simultânea para o ajustamento de variações de curto prazo em relação a níveis de longo prazo.

Desse modo, o modelo VEC, utilizado nesse estudo, pode ser descrito da seguinte forma:

$$
\Delta Y_{t}=\pi_{0}+\phi Y_{t-1}+\sum_{i=1}^{4} \pi_{i} \Delta Y_{t-i}+\varepsilon_{t}
$$

Onde, $\pi_{0} \pi_{0}$ é o vetor (n x 1) dos termos de 
intercepto; $\pi_{i} \pi_{i}$ é a matriz ( $\mathrm{n} \times \mathrm{n}$ ) associada aos parâmetros das variáveis do modelo; $\phi \phi$ é o vetor ( $\mathrm{n} \times 1$ ) de cointegração ou os coeficientes de ajuste de longo prazo do modelo; e $\varepsilon_{t} \varepsilon_{t}$ é o vetor (n x 1 ) de resíduos. São utilizadas quatro defasagens. É aplicado ajuste sazonal em todas as variáveis. $\mathrm{O}$ método utilizado é o Census X12.

Para a estimação dos modelos com base na metodologia apresentada, são necessários alguns testes de especificações com intuito de diagnosticar as análises. Inicialmente, testa-se a presença de raiz unitária, a qual tem por finalidade identificar se as séries inseridas no modelo apresentam relação de estacionariedade. Os testes propostos para identificar se as séries possuem médias e variâncias constantes ao longo do tempo foram determinados com base nos testes de ADF (Augmented Dickey-Fuller) e PP (Phillips-Perron). Após o teste de raiz unitária, emprega-se o teste cointegração para identificar se as variáveis possuem uma relação de equilíbrio de longo prazo. Logo, o conceito de cointegração consiste em uma combinação linear estacionária entre as variáveis inseridas em determinado modelo ${ }^{1}$. Neste estudo é utilizado o teste de cointegração de Johansen com o objetivo de identificar os vetores de cointegração nos modelos. Os critérios de Akaike (AIC) e Schwarz (SC), num contex to multi equacional, são utilizados para a determinação dos melhores modelos, sendo que a escolha se dá pelos menores números gerados por ambos os testes. Posteriormente, aplica-se o teste de auto correlação dos resíduos com o intuito de investigar a possibilidade de que erros sucessivos estejam correlacionados nas séries. Em relação à normalidade dos resíduos, testa-se se os mesmos são normalmente distribuídos e possuem probabilidade de variável aleatória. Para tanto, utiliza-se o método estatístico Jarque-Bera (JB), o qual se caracteriza por ser um teste assintótico devido a calcular, primeiramente, a assimetria e a curtose. Com o propósito de verificar a estabilidade dos modelos, aplica-se o teste de raiz inversa para modelos auto regressivos (AR).

Em relação à captação da intensidade dos choques nas variáveis, analisam-se, por meio da ferramenta impulso resposta, os efeitos das variações individuais sobre a dinâmica do sistema, com o objetivo de mostrar como um choque em determinada variável afeta as demais variáveis no decorrer do tempo. Para determinar tal análise, utiliza-se o teste de causalidade de Granger, o qual permite identificar e prever se determinada variável impacta no desempenho de outra.

1Segundo Banerjee et al. (1993), quando duas variáveis yt e zt possuem ordem de integração I(1), ou seja, são definidas como não estacionárias, logo o modelo linear yt $=\square$ zt $+\square \mathrm{t}$ também será $\mathrm{I}(1)$.

\subsection{VARIÁVEIS UTILIZADAS E FONTE DOS DADOS}

As séries temporais utilizadas na análise empírica possuem periodicidade trimestral. O período utilizado é do primeiro trimestre de 1995 ao último de 2009. As séries de produção brasileira de açúcar (S_AC) e álcool (S_ALC) foram obtidas pelo índice de produção física industrial a partir do Instituto Brasileiro de Geografia e Estatística (IBGE). O índice da produção de álcool é composto pelo total, no período, das produções do álcool hidratado e do álcool anidro. As exportações brasileiras de açúcar (X_AC) compreendem o valor exportado em milhões de dólares divulgados pela Secretaria de Comércio Exterior (SECEX). Estes valores foram convertidos em moeda nacional pela média mensal da taxa cambial publicada pelo Banco Central do Brasil (BACEN). Os preços recebidos pelo produtor de cana (PR_CAN) foram obtidos através do banco de dados do Instituto de Pesquisa Econômica Aplicada (IPEADATA), que consistem na média do valor pago em reais por tonelada de cana de açúcar produzida.

A série de preços do açúcar no varejo do mercado brasileiro (PV_AC) para o período considerado foi obtida no Instituto de Economia Agrícola (IEA-SP). Os preços obtidos correspondem à média de preço por quilo do açúcar no varejo. As séries de preço do álcool (P_ALC) e da gasolina (P_GAS) foram obtidas a partir do Índice Nacional de Preços ao Consumidor Amplo (IPCA), divulgado pelo IBGE. A variável taxa cambial (EXC_R) consiste na média da taxa de câmbio nominal do período, expressa em unidades de moeda nacional sobre uma unidade de dólar dos Estados Unidos da América (EUA), publicada pelo BACEN.

\subsection{TESTES DE ESPECIFICAÇÃO}

Inicia-se o processo investigativo por meio do teste de raiz unitária, o qual consiste verificar a existência de tendência estocástica nas variáveis.

Os resultados para todas as séries indicam a presença de raiz unitária de ordem de integração I(1). Todavia, as séries tornam-se estacionárias I(0) quando as mesmas são testadas em diferença ${ }^{2}$.

O procedimento seguinte foi verificar a relação de equilíbrio de longo prazo dos modelos. $\mathrm{O}$ método utilizado foi o teste de Johansen, o qual indica ser possível rejeitar a hipótese nula de não existência de cointegração. Dessa forma, as variáveis inseridas possuem equilíbrio de longo

2 Os resultados encontram-se no Apêndice. 
Tabela 1: Teste de cointegração de Johansen com quatro defasagens

\begin{tabular}{c|c|c|c|c|c}
\hline \multirow{2}{*}{ № de vetores de cointegração } & \multirow{2}{*}{ Autovalor } & Estatística & Valor & Estatística & Valor \\
\cline { 3 - 6 } & & Traço & Crítico* & Max. Autovalor & Crítico** \\
\hline$r=0$ & 0.908818 & 445.1510 & 159.5297 & 131.7194 & 52.36261 \\
\hline$r \leq 1$ & 0.827965 & 313.4315 & 125.6154 & 96.80311 & 46.23142 \\
\hline$r \leq 2$ & 0.757887 & 216.6284 & 95.75366 & 78.00935 & 40.07757 \\
\hline$r \leq 3$ & 0.715938 & 138.6191 & 69.81889 & 69.22089 & 33.87687 \\
\hline$r \leq 4$ & 0.472433 & 69.39818 & 47.85613 & 35.17134 & 27.58434 \\
\hline$r \leq 5$ & 0.305190 & 34.22684 & 29.79707 & 20.02646 & 21.13162 \\
\hline$r \leq 6$ & 0.139253 & 14.20038 & 15.49471 & 8.247488 & 14.26460 \\
\hline$r \leq 7$ & 0.102583 & 5.952891 & 3.841466 & 5.952891 & 3.841466 \\
\hline
\end{tabular}

Notas: (*) Estatística Traço indica 6 vetores de cointegração ao nível de 5\% de significância. (**) Estatística Máximo autovalor indica 5 vetores de cointegração ao nível de 5\% de significância.

Tabela 2: Testes de auto correlação Lagrange Multiplier (LM-Test)

\begin{tabular}{c|c|c|c|c|c|c|c|c}
\hline & \multicolumn{2}{|c|}{1} & \multicolumn{2}{c|}{2} & \multicolumn{2}{c}{3} & \multicolumn{2}{c}{4} \\
\hline Lags & LM-Stat & Prob & LM-Stat & Prob & LM-Stat & Prob & LM-Stat & Prob \\
\hline 1a & 71.75848 & 0.2363 & 70.70982 & 0.2637 & 75.35459 & 0.1568 & 53.59405 & 0.8199 \\
\hline 2a & 71.44983 & 0.2442 & 68.89262 & 0.3154 & 64.32615 & 0.4650 & 66.05482 & 0.4057 \\
\hline 3a & 60.05689 & 0.6166 & 66.31778 & 0.3970 & 73.79600 & 0.1885 & 58.62386 & 0.6663 \\
\hline 4a & 108.7531 & 0.0004 & 93.21317 & 0.0100 & 59.37898 & 0.6403 & 62.33481 & 0.5356 \\
\hline
\end{tabular}

Tabela 3: Testes de normalidade dos resíduos

\begin{tabular}{|c|c|c|c|c|c|c|c|c|c|}
\hline \multirow{2}{*}{ Lags } & \multicolumn{3}{|c|}{ Cholesky (Lutkepohl) } & \multicolumn{3}{|c|}{ Doornik-Hansen } & \multicolumn{3}{|c|}{ Urzúa } \\
\hline & Jarque-Bera & $\mathrm{Df}$ & Prob. & Jarque-Bera & Df & Prob. & Jarque-Bera & Df & Prob. \\
\hline $1 \underline{a}$ & 100.2553 & 16 & 0.0000 & 72.37826 & 16 & 0.0000 & 727.9019 & 450 & 0.0000 \\
\hline $2 \underline{a}$ & 63.93948 & 16 & 0.0000 & 53.51961 & 16 & 0.0000 & 634.4129 & 450 & 0.0000 \\
\hline $3 \underline{a}$ & 40.76839 & 16 & 0.0006 & 56.94544 & 16 & 0.0000 & 622.7362 & 450 & 0.0000 \\
\hline $4 \underline{a}$ & 17.73184 & 16 & 0.3398 & 46.52641 & 16 & 0.0001 & 440.1634 & 450 & 0.6210 \\
\hline
\end{tabular}


prazo e o modelo autorregressivo com mecanismo correção de erros pode ser utilizado. A Tabela 1 apresenta esses resultados.

No que tange aos testes de autocorrelação dos resíduos, a Tabela 2 apresenta os resultados para o modelo com até quatro defasagens ${ }^{3}$.

De acordo com as probabilidades estatísticas dos testes apresentados, assume-se a hipótese nula de ausência de autocorrelação com $95 \%$ de confiança. O teste de normalidade dos resíduos é realizado através da estatística de Jarque-Bera, o qual indica que a hipótese nula não pode ser rejeitada no modelo com quatro defasagens, tanto no teste de Cholesky (Lutkepohl) como no de Urzúa (Tabela 3).

A Figura 1 mostra que o modelo com quatro defasagens é estável. Isso se deve pelo fato de que as raízes inversas do polinômio característico autorregressivo encontram-se dentro do círculo unitário.

Figura 1: Raízes inversas com quatro defasagens

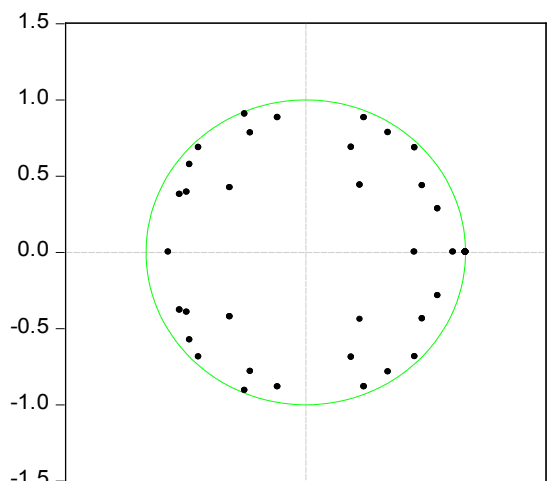

Desse modo, conclui-se que o modelo utilizando quatro defasagens apresentou consistência e robustez, devido aos resultados dos testes aplicados. Assim, as análises das funções impulso resposta e causalidade de Granger são efetuadas.

\section{RESULTADOS E DISCUSSÃO}

Para uma melhor compreensão das funções impulso resposta do modelo escolhido4, aplicam-se os testes de causalidade de Granger para o modelo com quatro defasagens com intuito de prever a influência que uma variável exerce sobre a outra.

$3 \mathrm{O}$ modelo com quatro defasagens apresentou resultados consistentes e com maior robustez em relação aos demais níveis de defasagens (lags 1, 2 e 3).

4 As variáveis que compõe o modelo podem ser observadas na tabela 4 do teste de causalidade de Granger.
De acordo com a Tabela 4, ao nível de significância de $5 \%$, a produção de açúcar causa, no sentido de Granger, o preço da gasolina. Tal resultado pode ser justificado, partindo do princípio de que a oferta de açúcar pode influenciar o comportamento do preço do álcool, que, por sua vez, em parte, pode afetar o preço da gasolina5. Ao mesmo nível de significância, os testes destacam que a produção de álcool causa o preço da gasolina. Logo, esse resultado corrobora com a teoria econômica por se tratarem de bens substitutos ou complementares, onde oscilações no preço de um impactam diretamente na quantidade ofertada do outro.

O preço do açúcar no varejo, a $5 \%$ de significância, também causa o preço recebido pelo produtor de cana, o que, de certa forma, pode impactar positivamente na oferta brasileira de açúcar. Já ao nível de significância de $10 \%$, os resultados estimados com base nos testes de Granger6 apontam que variações no preço do açúcar no varejo causam o preço do álcool. No mesmo sentido das análises anteriores, esse comportamento pode ser causado pela decisão do produtor em ofertar açúcar e álcool7.

De acordo com a Figura 2, observam-se as respostas a um impulso da variável exportação de açúcar sobre as demais variáveis endógenas. A resposta da variável produção de açúcar (2.1) sobre um impulso generalizado na exportação de açúcar indica uma tendência de comportamento positivo ao longo dos períodos, apenas com uma exceção negativa no quarto trimestre. No mesmo sentido, em relação ao comportamento da produção álcool (2.2), o resultado é adequado com a dinâmica do setor. Em outras palavras, um choque na exportação de açúcar gera um impacto negativo na oferta de álcool (2.2), uma vez que a elevação da demanda por exportações de açúcar motive a decisão do produtor em detrimento do álcool.

As respostas das variáveis preço recebido pelo produtor de cana (2.4) e preço do açúcar no varejo (2.5) possuem relação positiva a um impulso nas exportações de açúcar. Tal resultado corrobora com a teoria de oferta agrícola no sentido em que o aumento do preço da matéria prima e do açúcar no mercado interno, em parte, pode ser decorrente do aumento da demanda externa. A resposta das

\footnotetext{
5 Pressupõe-se que o preço da gasolina é causado por outros fatores não relacionados neste estudo, tais como preço do barril do petróleo, produção de gasolina e derivados.

7 Uma breve definição e exemplos em relação aos testes de Granger podem ser encontrados em Bueno (2008).

7 Os demais resultados não comentados na Tabela 4, não são conclusivos quanto à ordem de precedência e, assim, faz-se necessário avaliar as funções impulso resposta.
} 
Tabela 4: Teste de causalidade de Granger

\begin{tabular}{|c|c|c|c|c|c|}
\hline Hipótese Nula & Estatística-F & Prob. & Hipótese Nula & Estatística-F & Prob. \\
\hline$\Delta S \_A L C$ não causa $\Delta S \_A C$ & 0.7871 & 0.5395 & $\Delta \mathrm{PV} \_\mathrm{AC}$ não causa $\Delta \mathrm{X} \_\mathrm{AC}$ & 0.6919 & 0.6014 \\
\hline$\Delta S \_A C$ não causa $\Delta S \_A L C$ & 1.0284 & 0.4028 & $\Delta \mathrm{X} \_\mathrm{AC}$ não causa $\Delta \mathrm{PV} \_\mathrm{AC}$ & 0.2171 & 0.9276 \\
\hline$\Delta \mathrm{X} \_\mathrm{AC}$ não causa $\Delta \mathrm{S} \_\mathrm{AC}$ & 3.5245 & 0.0137 & $\Delta \mathrm{EXC} R$ não causa $\Delta \mathrm{X} \_\mathrm{AC}$ & 1.1965 & 0.3251 \\
\hline$\Delta \mathrm{S} \_\mathrm{AC}$ não causa $\Delta \mathrm{X} \_\mathrm{AC}$ & 0.7335 & 0.5738 & $\Delta \mathrm{X} \_\mathrm{AC}$ não causa $\Delta \mathrm{EXC} \mathrm{R}$ & 0.2928 & 0.8811 \\
\hline$\Delta \mathrm{PR} \_C A N$ não causa $\Delta S \_A C$ & 0.3198 & 0.8632 & $\Delta \mathrm{P} \_\mathrm{ALC}$ não causa $\Delta \mathrm{X} \_\mathrm{AC}$ & 0.7980 & 0.6942 \\
\hline$\Delta S \_A C$ não causa $\Delta \mathrm{PR} \_C A N$ & 0.3964 & 0.8102 & $\Delta \mathrm{X} \_\mathrm{AC}$ não causa $\Delta \mathrm{P} \_\mathrm{ALC}$ & 1.8045 & 0.1442 \\
\hline$\triangle \mathrm{PV} \_A C$ não causa $\Delta \mathrm{S} \_\mathrm{AC}$ & 0.6011 & 0.6638 & $\Delta \mathrm{P} \_\mathrm{GAS}$ não causa $\Delta \mathrm{X} \_\mathrm{AC}$ & 1.2280 & 0.3121 \\
\hline$\Delta S \_A C$ não causa $\Delta P V \_A C$ & 0.2258 & 0.9226 & $\Delta \mathrm{X} \_\mathrm{AC}$ não causa $\Delta \mathrm{P} \_\mathrm{GAS}$ & 1.2685 & 0.2961 \\
\hline$\Delta \mathrm{EXC} R \mathrm{R}$ não causa $\Delta \mathrm{S} \_\mathrm{AC}$ & 0.3269 & 0.8585 & $\triangle \mathrm{PV} \_\mathrm{AC}$ não causa $\triangle \mathrm{PR} \_\mathrm{CAN}$ & 3.6083 & 0.0122 \\
\hline$\Delta S \_A C$ não causa $\triangle E X C \_R$ & 0.8276 & 0.5145 & $\triangle P R \_C A N$ não causa $\triangle P V \_A C$ & 0.8313 & 0.5122 \\
\hline$\Delta \mathrm{P} \_\mathrm{ALC}$ não causa $\Delta \mathrm{S} \_\mathrm{AC}$ & 0.8714 & 0.4883 & $\triangle E X C \_R$ não causa $\triangle P R \_C A N$ & 0.7527 & 0.5614 \\
\hline$\Delta S \_A C$ não causa $\Delta P \_A L C$ & 1.3413 & 0.2691 & $\triangle P R \_C A N$ não causa $\triangle E X C \_R$ & 0.1901 & 0.9424 \\
\hline$\Delta \mathrm{P} \_\mathrm{GAS}$ não causa $\Delta \mathrm{S} \_\mathrm{AC}$ & 0.6097 & 0.6577 & $\triangle P \_A L C$ não causa $\triangle P R \_C A N$ & 1.5830 & 0.2021 \\
\hline$\Delta S \_A C$ não causa $\Delta P \_G A S$ & 5.1013 & 0.0017 & $\triangle \mathrm{PR} \_C A N$ não causa $\Delta \mathrm{P} \_\mathrm{ALC}$ & 0.0401 & 0.9968 \\
\hline$\Delta \mathrm{X} \_\mathrm{AC}$ não causa $\Delta \mathrm{S} \_\mathrm{ALC}$ & 0.8500 & 0.5010 & $\triangle \mathrm{P} \_\mathrm{GAS}$ não causa $\triangle \mathrm{PR} \_\mathrm{CAN}$ & 1.3061 & 0.2818 \\
\hline$\Delta \mathrm{S} \_\mathrm{ALC}$ não causa $\Delta \mathrm{X} \_\mathrm{AC}$ & 38 & 0.8120 & $\Delta \mathrm{PR} \overline{\mathrm{C}} \mathrm{CAN}$ não causa $\Delta \mathrm{P} \_\mathrm{GAS}$ & 0.4864 & 0.7456 \\
\hline$\Delta \mathrm{PR} \_C A N$ não causa $\Delta S \_A L C$ & 254 & 0.9726 & $\triangle E X C \_R$ não causa $\triangle P V \_A C$ & & 0.3957 \\
\hline$\Delta S \_A L C$ não causa $\Delta P R \_C A N$ & 0.5785 & 0.6797 & $\Delta \mathrm{PV} \_\mathrm{AC}$ não causa $\triangle \mathrm{EXC} R$ & 0.5439 & 0.7043 \\
\hline$\Delta \mathrm{PV} \_\mathrm{AC}$ não causa $\Delta \mathrm{S} \_\mathrm{ALC}$ & 1.5802 & 0.1956 & $\Delta \mathrm{P} \_A L C$ não causa $\triangle \mathrm{PV} \_\mathrm{AC}$ & 1.0452 & 0.3943 \\
\hline$\Delta \mathrm{S} \_A L C$ não causa $\Delta \mathrm{PV} \_\mathrm{AC}$ & 1.1022 & 0.3669 & $\triangle P V \_A C$ não causa $\triangle P \_A L C$ & 2.1495 & 0.0898 \\
\hline$\Delta E X C \_R$ não causa $\Delta S \_A L C$ & 0.7041 & 0.5932 & $\Delta \mathrm{P} \_\mathrm{GAS}$ não causa $\triangle \mathrm{PV} \_\mathrm{AC}$ & 1.7840 & 0.1483 \\
\hline$\Delta S \_A L C$ não causa $\Delta E X C \_R$ & 0.4501 & 0.7718 & $\Delta \mathrm{PV} \_\mathrm{AC}$ não causa $\Delta \mathrm{P} \_\mathrm{GAS}$ & 0.9294 & 0.4300 \\
\hline$\Delta \mathrm{P} \_\mathrm{ALC}$ não causa $\Delta \mathrm{S} \_\mathrm{ALC}$ & 1.4151 & 0.2440 & $\Delta \mathrm{P} \_\mathrm{ALC}$ não causa $\Delta \mathrm{EXC} \_\mathrm{R}$ & 0.3705 & 0.8284 \\
\hline$\triangle S \_A L C$ não causa $\triangle P$ P_ALC & 1.3473 & 0.2669 & $\Delta \mathrm{EX} \overline{\bar{X}} \_\mathrm{R}$ não causa $\Delta \mathrm{P} \_\mathrm{ALC}$ & 1.1044 & 0.3659 \\
\hline$\Delta \mathrm{P} \_\mathrm{GAS}$ não causa $\Delta \mathrm{S} \_\mathrm{ALC}$ & 0.3200 & 0.8632 & $\Delta \mathrm{P} \_\mathrm{GAS}$ não causa $\Delta \mathrm{EXC} R$ & 0.1409 & 0.9661 \\
\hline$\Delta S \_A L C$ não causa $\Delta P \_G A S$ & 3.7831 & 0.0097 & $\Delta \mathrm{EXC} \_\mathrm{R}$ não causa $\Delta \mathrm{P} \_\mathrm{GAS}$ & 1.8849 & 0.1292 \\
\hline$\Delta P R \_C A N$ não causa $\Delta \mathrm{X} \_A C$ & 1.6180 & 0.1864 & $\Delta \mathrm{P} \_\mathrm{GAS}$ não causa $\Delta \mathrm{P} \_\mathrm{ALC}$ & 1.9098 & 0.1248 \\
\hline$\Delta \mathrm{X} \_A C$ não causa $\Delta \mathrm{PR} \_\mathrm{CAN}$ & 0.6358 & 0.6396 & $\Delta \mathrm{P} \_A L C$ não causa $\Delta \mathrm{P} \_\mathrm{GAS}$ & 0.4890 & 0.7438 \\
\hline
\end{tabular}

Notas: 55 observações, entre o período de 1995 a 2009 (quatro defasagens). S_AC: oferta de açúcar; X_AC: exportação de açúcar; S_ALC: produção de álcool; PI_AC: preço internacional do açúcar; PR_CAN: preço recebido pelo produtor de cana; P_ALC: preço do álcool; EXC_R: taxa de câmbio; PV_AC: preço do varejo do açúcar; P_GAS: preço da gasolina.

exportações de açúcar (2.3) apresentou relação positiva no que diz respeito ao próprio impulso. Por sua vez, o comportamento da variável preço do álcool (2.6) não apresentou resultados condizentes ao esperado devido à queda do preço, tornando a resposta contra intuitiva.

A resposta da variável preço da gasolina (2.7) a um choque nas exportações de açúcar indica também um resultado contraintuitivo, uma vez que o preço da gasolina pode ser influenciado por outros fatores8.

No que se refere à resposta do preço recebido pelo produtor de cana (3.3) em relação a um impulso na produção brasileira de açúcar, a Figura 3 indica um comportamento negativo ao

8 Os fatores podem estar relacionados com a produção de gasolina, preço do petróleo, interferências governamentais, entre outros. longo dos períodos analisados. Tal resultado não está adequado com o esperado, devido ao fato de que uma expansão na oferta deveria provocar um aumento no preço da matéria prima.

O comportamento da variável preço do açúcar no varejo (3.4) também apresenta resultados negativos em relação a choques na oferta de açúcar, o que corrobora com o impulso da produção de açúcar. Ademais, este resultado apresenta sinais coerentes com a teoria de oferta, pois a expansão da oferta provoca no sentido contrário uma queda nos preços. A resposta da produção de álcool (3.2) mostra que os mesmos fatores que causaram o aumento de produção de açúcar causam também a elevação na produção de álcool, determinando um resultado positivo. Da mesma maneira, esse efeito impacta negativamente no comportamento da variável preço do álcool (3.5). 

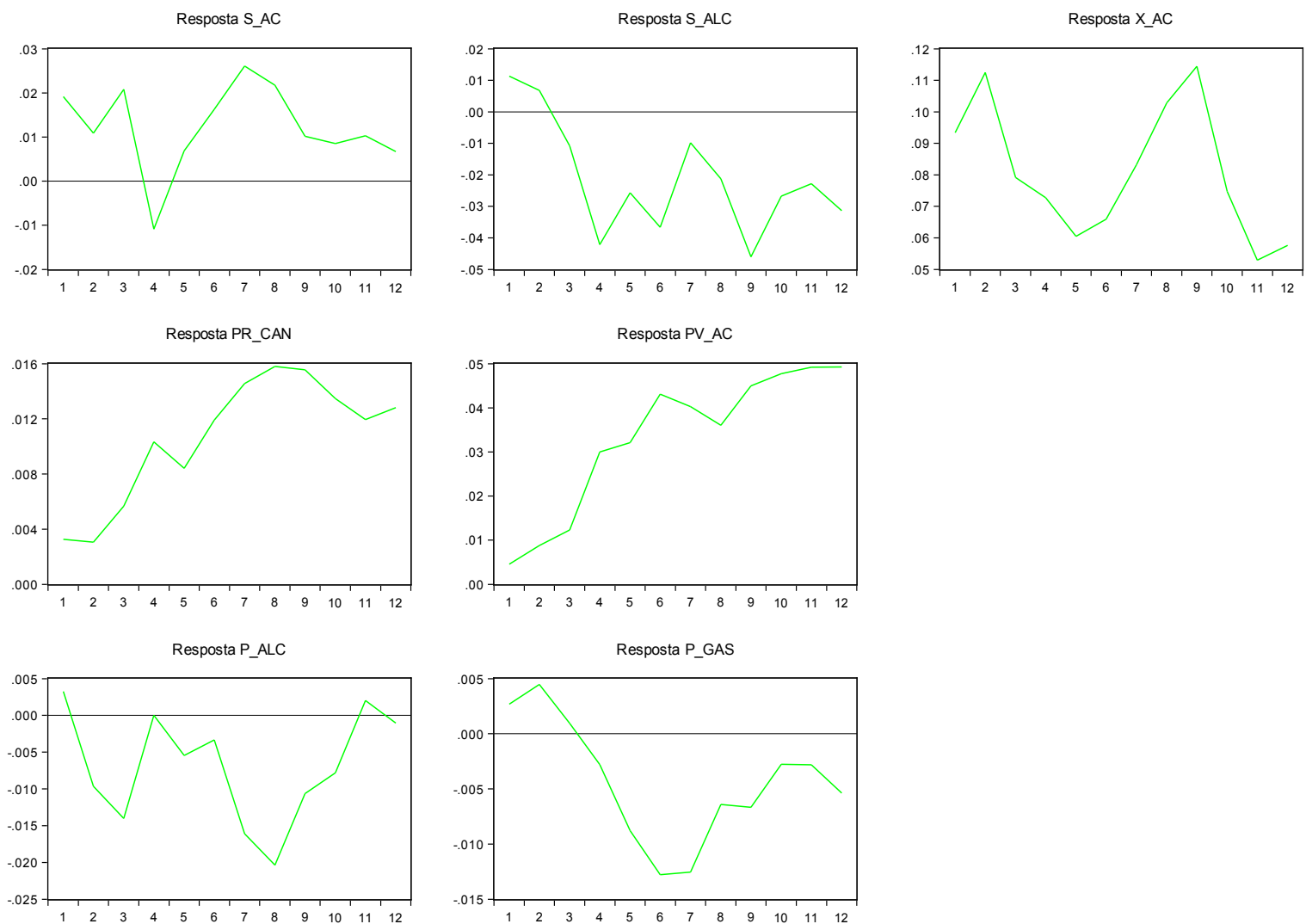

Figura 2: Resposta a um impulso generalizado na variável exportação brasileira de açúcar (X_AC)
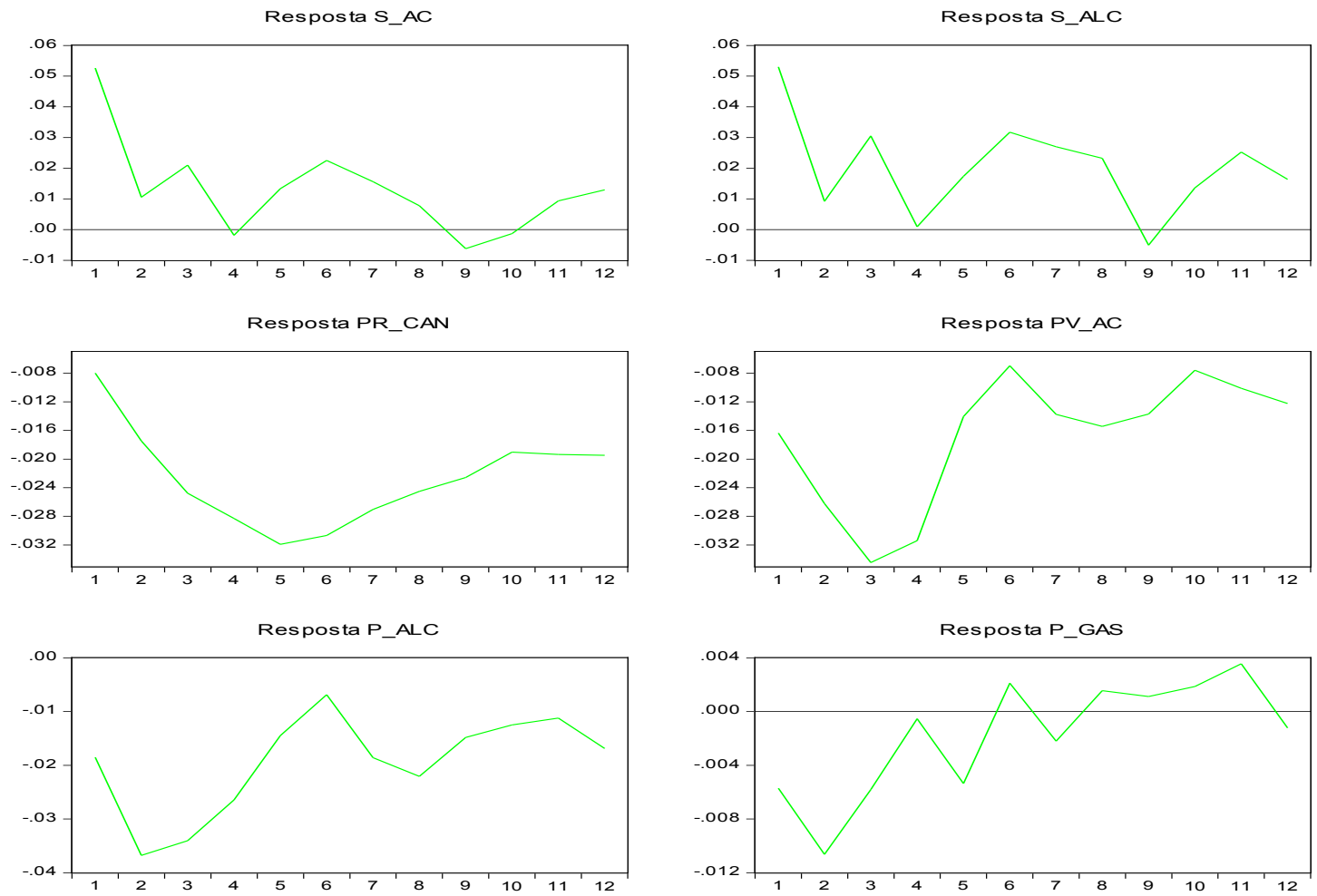

Figura 3: Resposta a um impulso generalizado na variável produção brasileira de açúcar (S_AC) 
Resposta S_AC

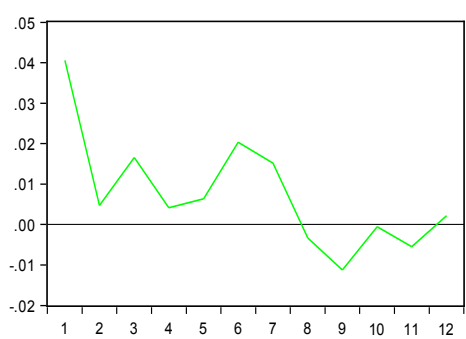

Resposta PR_CAN

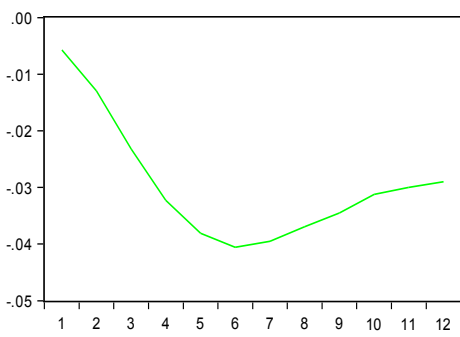

Resposta P_ALC

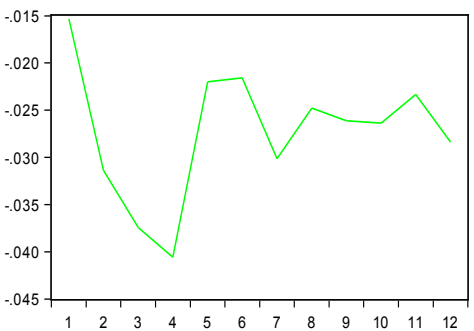

Resposta S_ALC

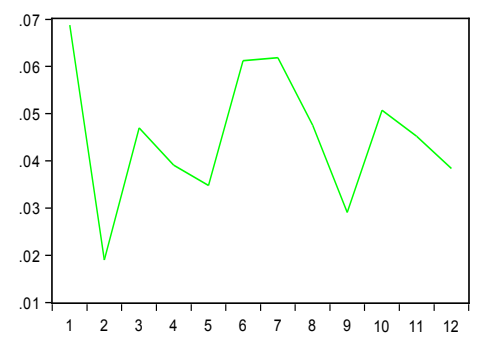

Resposta PV_AC

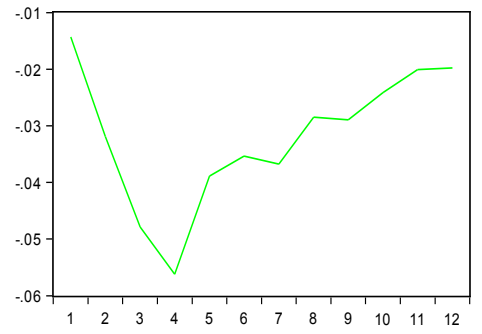

Resposta P_GAS

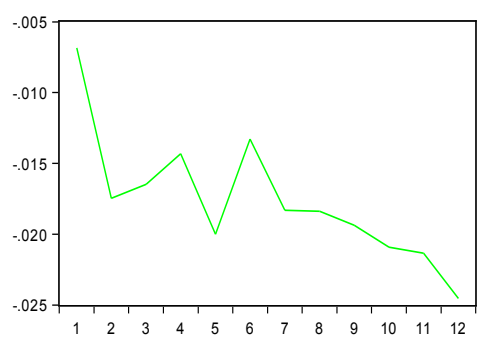

Figura 4: Resposta a um impulso generalizado na variável produção brasileira de álcool (S_ALC)

No que tange à reposta do preço da gasolina (3.6) no curto prazo, os resultados apresentam uma tendência negativa e a partir do sétimo trimestre uma reposta positiva que tende a se manter no longo prazo. Esse resultado pode ser interpretado com base no comportamento do preço do álcool, que oscila negativamente, motivando no mesmo sentido a queda no preço da gasolina no curto prazo. Contudo, a resposta da produção de açúcar (3.1) sobre a própria produção apresenta resultado positivo e persistente ao longo prazo.A Figura 4 mostra o impulso de um choque generalizado da variável produção brasileira de álcool nas variáveis endógenas. Nota-se que a resposta da produção de açúcar (4.1) é positiva em quase todos os períodos, justificando a análise do impulso anterior. Todavia, o comportamento é negativo a partir do oitavo trimestre, porém as oscilações são pouco significativas e tendem ao patamar zero.

A resposta da produção de álcool (4.2) sobre o impulso da própria produção como já esperado, mostrou-se significativa e com efeito positivo. Observa-se uma consonância nas repostas do preço recebido pelo produtor de cana (4.4) e preço do açúcar no varejo (4.5) em relação ao impulso na produção de álcool. Ressalta-se que o resultado negativo do preço recebido pelo produtor de cana deve ser analisado com cautela, pois a produção de álcool determina e, em parte, impacta na formação dos preços recebidos. No que se refere à reposta da variável exportação de açúcar (4.3), o comportamento negativo foi coerente com o esperado devido à produção de álcool e açúcar dependerem da mesma matéria prima.

A resposta do preço do álcool (4.6) é negativa e acompanha o mesmo comportamento apresentado no modelo anterior, onde um impulso na oferta de álcool gera, no sentido contrário, uma redução do preço ao longo dos períodos. De acordo com o esperado, um impulso na produção de álcool gerou impacto negativo em relação à variável preço da gasolina (4.7), que registrou maior queda no longo prazo?.

A Figura 5 apresenta as repostas das variáveis endógenas sobre um impulso no preço recebido pelo produtor de cana ${ }^{10}$. A resposta da exportação

9 Parte-se do pressuposto que um aumento da oferta de álcool, que reduz seu preço, pode em parte motivar uma queda no preço da gasolina.

10 A resposta da variável preço do açúcar no varejo não foi analisada 
Resposta S AC

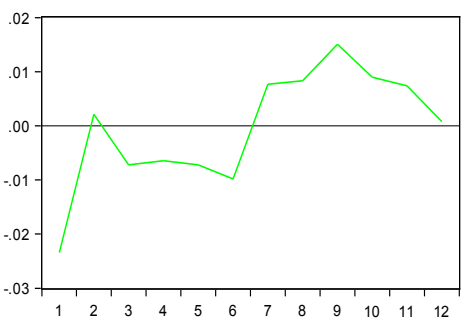

Resposta PR CAN

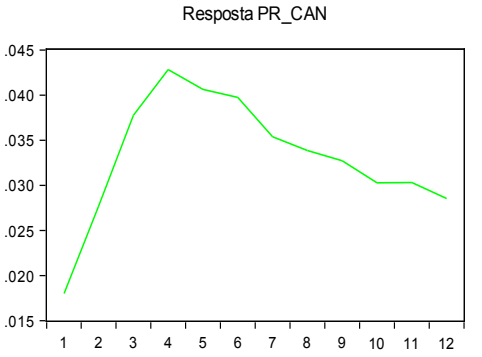

Resposta S ALC
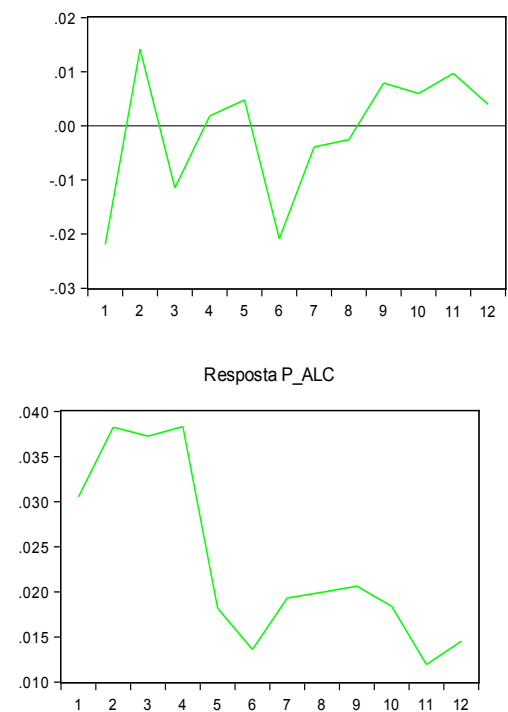

Resposta X_AC

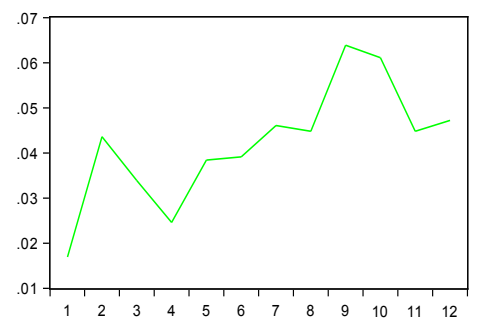

Resposta P_GAS

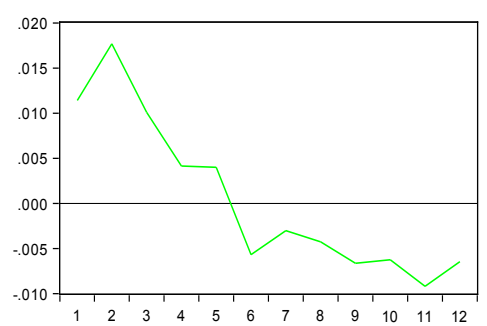

Figura 5: Resposta a um impulso generalizado na variável preço recebido pelo produtor de cana de açúcar (PR_CAN)

Resposta S AC

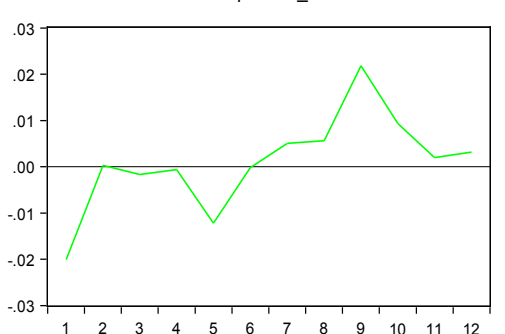

Resposta PR_CAN

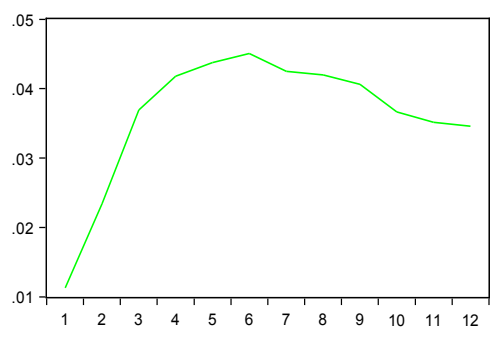

Resposta P_ALC

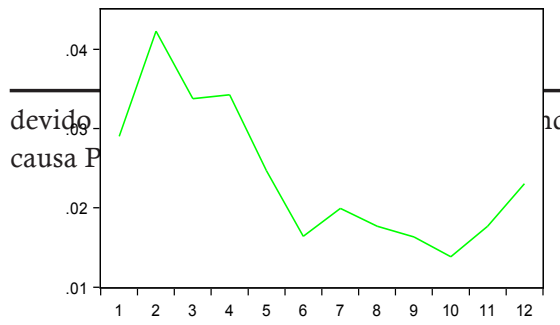

Resposta S ALC

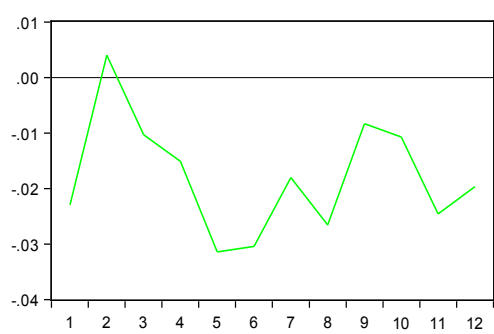

Resposta PV_AC

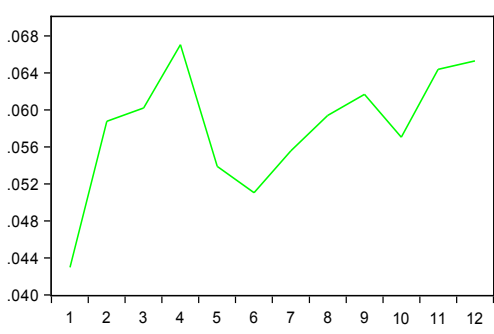

Resposta P_GAS

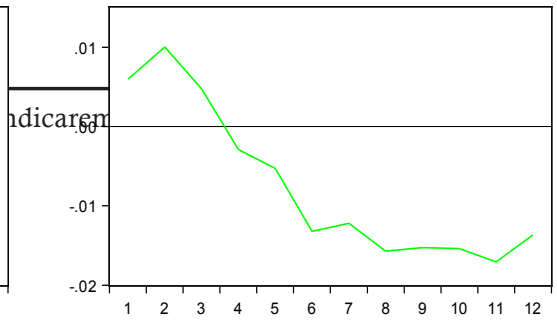

Resposta X AC

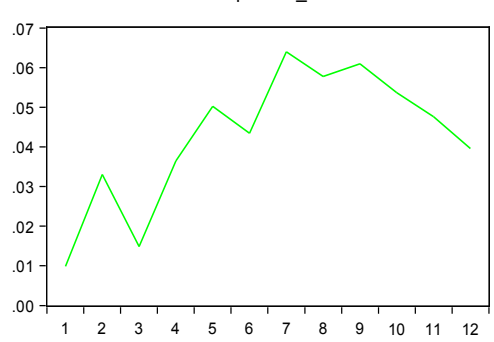

Figura 6: Resposta a um impulso generalizado na variável preço do açúcar no varejo (PV_AC) 

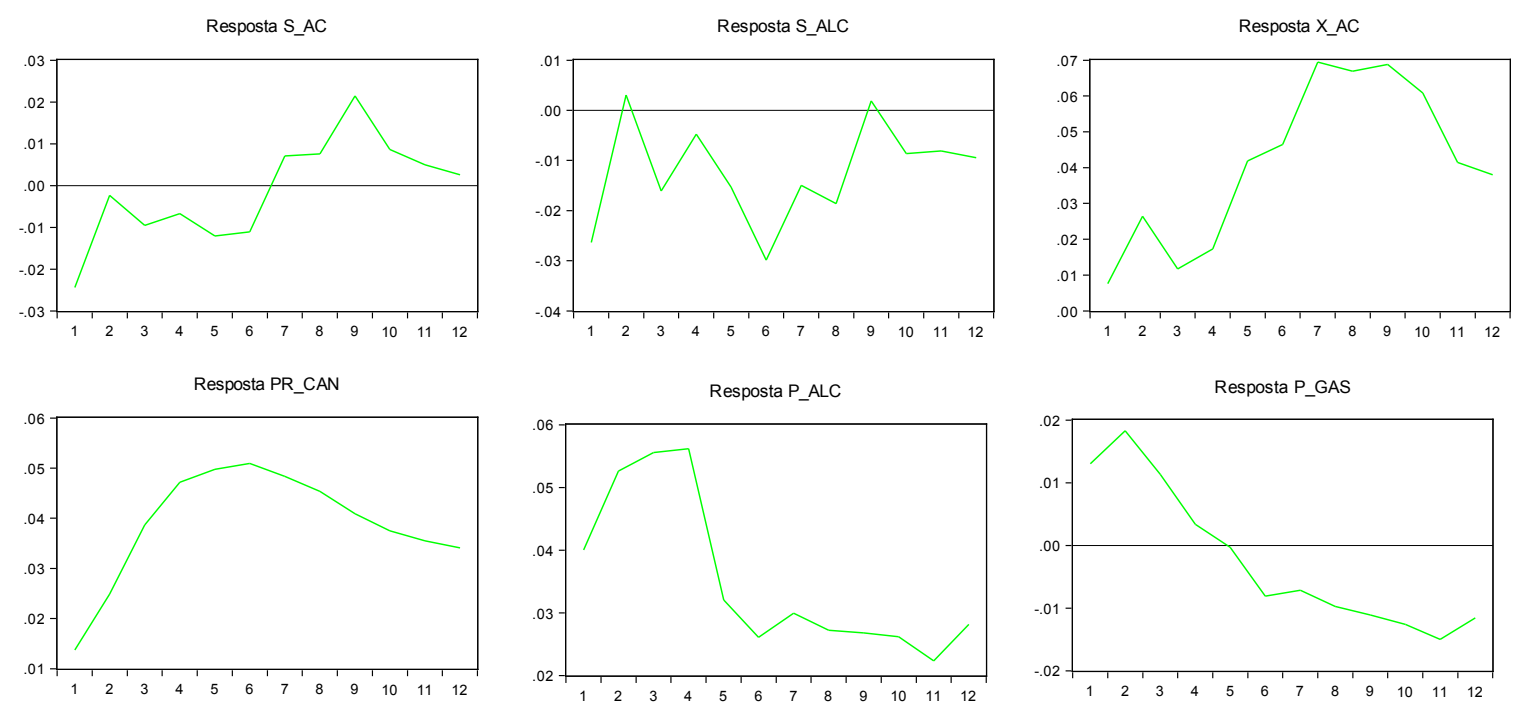

Figura 7: Resposta a um impulso generalizado na variável preço do álcool (P_ALC)

de açúcar (5.3) é positiva e tende a justificar o comportamento do setor. Esse resultado pode indicar que um impulso no preço recebido pelo produtor motiva um aumento da oferta de açúcar, contribuindo, assim, para o crescimento das exportações brasileiras.

As respostas das produções de álcool (5.2) e produção de açúcar (5.1) em relação a um impulso no preço recebido pelo produtor de cana apresentam resultados semelhantes e indicam que um possível aumento no preço recebido pelo produtor motive um crescimento de ambos os produtos no longo prazo, pois o impulso pode expandir oferta futura da matéria prima. A resposta do preço recebido pelo produtor de cana (5.4) a um próprio impulso, como já esperado, gera um impacto positivo.

O comportamento do preço do álcool (5.5) é positivo a um impulso no preço recebido pelo produtor de cana. Logo, este fato, em parte, pode ser justificado também pela elevação dos custos de produção do álcool.

A resposta do preço da gasolina (5.6) é positiva, aproximadamente, até o quinto trimestre e negativa nos trimestres subsequentes. Uma possível explicação para esse comportamento pode se dar devido ao fato de que o impulso no preço recebido pelo produtor de cana, que em parte pode ser explicado por uma elevação da oferta de álcool, motiva uma queda no preço da gasolina no longo prazo $^{11}$.

11 Ressalta-se que apesar desse indício, não se pode afirmar
Um impulso generalizado no preço do açúcar do varejo pode ser observado na Figura 6 , destacando-se o comportamento inverso da variável produção de álcool (6.2). A resposta negativa, em parte, pode ser justificada devido ao um impulso no preço do açúcar do varejo motivar no mesmo sentido a decisão do produtor em ofertar mais açúcar. Em contrapartida, a resposta do preço do álcool (6.6) é positiva a um impulso do preço do açúcar no varejo. Logo, este fato corrobora com a análise anterior, indicando que um possível aumento de preço do álcool pode ser oriundo de uma redução na oferta do produto decorrente do impulso no preço do açúcar no varejo. A resposta do preço do açúcar no varejo (6.5) é positiva e apresenta comportamento de acordo com o esperado.

A resposta da variável preço recebido pelo produtor de cana (6.4) é positiva ao longo dos períodos, atingindo maior elevação, aproximadamente, no sexto trimestre. Pode se concluir que um impulso no preço do açúcar no varejo motive no mesmo sentido uma elevação no preço recebido pelo produtor.

Em relação à resposta da variável exportação de açúcar (6.3), a mesma apresenta comportamento positivo com tendência de evolução no longo prazo. Contudo, a variável produção de açúcar (6.1) é negativa no curto prazo, indicando que um impulso no preço do açúcar varejo pode causar, inicialmente, uma redução nas quantidades

que somente que este fato afete o comportamento do preço da gasolina. Ademais deve se analisar outros fatores tais como custo de prospecção e formação do preço do petróleo no mercado internacional. 

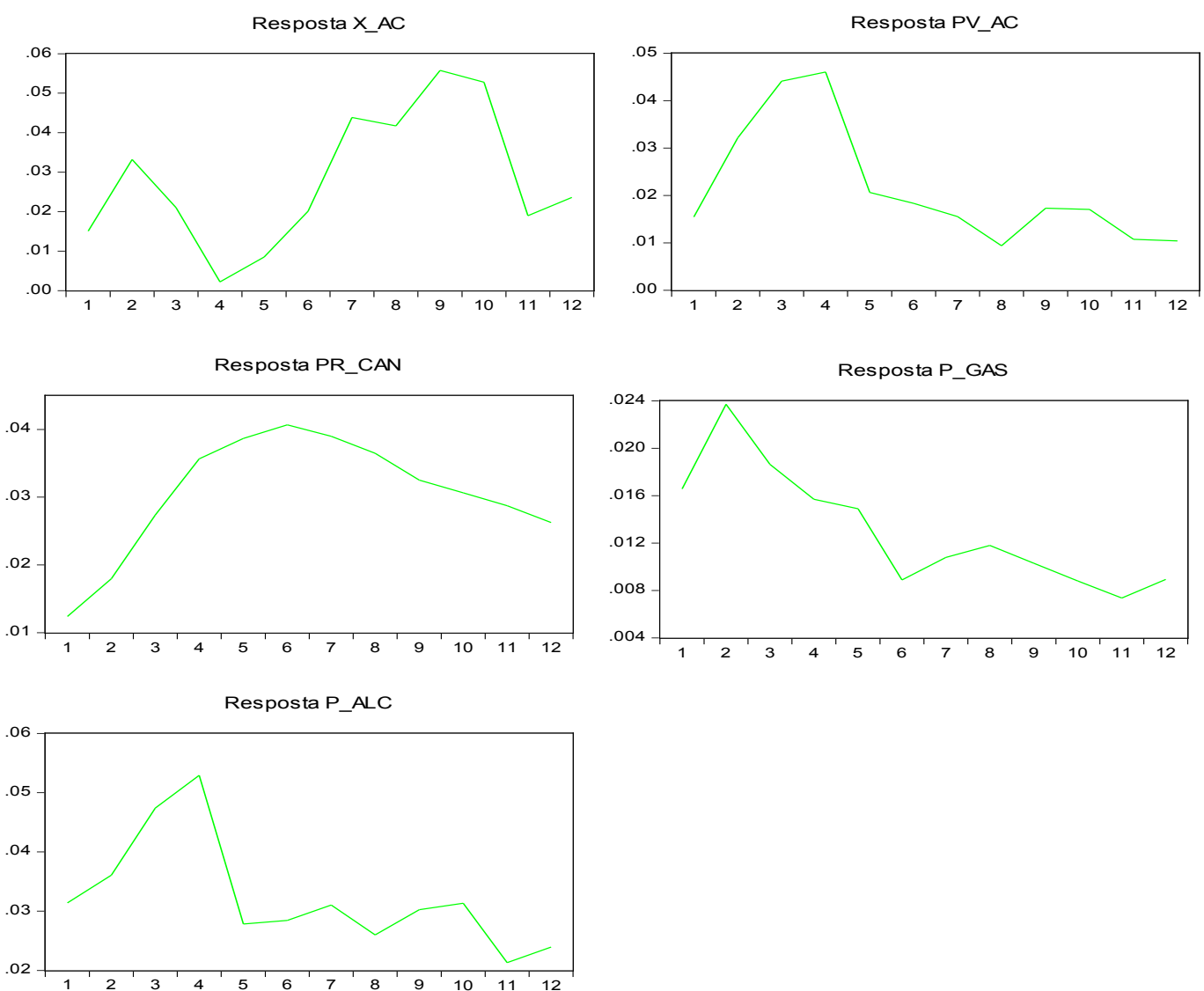

Figura 8: Resposta a um impulso generalizado na variável preço da gasolina (P_GAS)
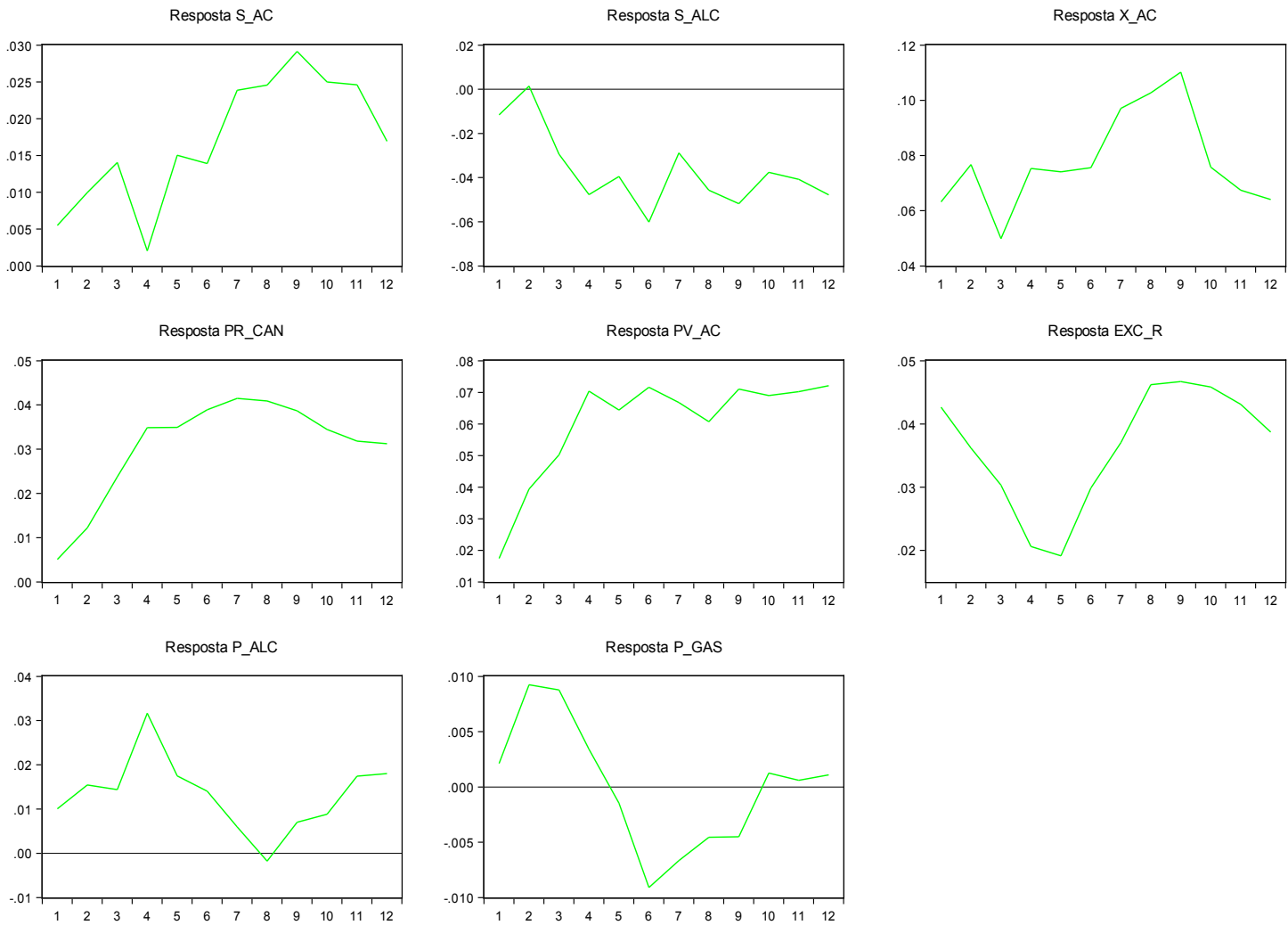

Figura 9: Resposta a um impulso generalizado na variável taxa de câmbio (EXC_R) 
ofertadas. A partir do sétimo trimestre, a reposta é positiva, o que pode indicar uma elevação no longo prazo da oferta decorrente de um impulso no preço do açúcar no varejo. A resposta da variável preço da gasolina (6.7) em relação a um impulso no preço do açúcar no varejo apresentou comportamento semelhante ao impulso generalizado da Figura 5, sendo que os mesmo motivos podem, em parte, explicar esse comportamento.

$\mathrm{Na}$ Figura 7 são apresentas as repostas das variáveis endógenas sobre um impulso generalizado no preço do álcool12. Nota-se que a reposta do preço recebido pelo produtor de cana (16.4) é positiva em relação a um impulso no preço do álcool. Este comportamento é adequado a um possível aumento da oferta de álcool.

A resposta da exportação de açúcar (7.3) é positiva e pode estar relacionada, caso o impulso no preço do álcool impactar no mesmo sentido na decisão do produtor em produzir açúcar. Logo, essa análise é duvidosa, pois a dinâmica do setor, geralmente, responde ao contrário e, neste caso, o mais esperado seria uma queda no comportamento das exportações decorrentes de um detrimento da produção de açúcar gerada por um impulso no preço do álcool.

A resposta do preço da gasolina (7.6) em relação a um impulso do preço do álcool é positiva até o quinto trimestre e negativa nos trimestres subsequentes. $\mathrm{O}$ resultado no curto prazo pode estar relacionado, caso o impulso do preço do álcool motive uma maior demanda por gasolina, inferindo, assim, no seu preço. No longo prazo, o comportamento é inconclusivo, pois pode estar sendo ocasionado por outros fatores não abordados neste estudo como a formação do preço internacional do petróleo.

As respostas das variáveis em relação a um impulso generalizado no preço da gasolina podem ser observadas na Figura 8. A variável preço da gasolina (8.4) em relação ao próprio impulso apresentou resultado positivo e de acordo com o esperado.

A resposta do preço do álcool (8.5) em relação a um impulso no preço da gasolina é positiva no longo prazo. Tal resultado, em parte, pode ser explicado por uma opção do consumidor em elevar a demanda por álcool devido a um choque no preço da gasolina. Ademais, observa-se que todas as respostas das demais variáveis em relação a um impulso no preço da gasolina também apresentaram resultados positivos. Desse modo,

12 A resposta do preço do açúcar no varejo não foi apresentada devido ao resultado positivo do teste de causalidade de Granger. esses comportamentos podem indicar que, em parte, as variáveis de exportação de açúcar (8.1), preço do açúcar no varejo (8.2) e preço recebido pelo produtor de cana (8.3) são influenciadas pelos movimentos no preço da gasolina. Em outras palavras, um choque no preço da gasolina pode ser benéfico para o setor, pois tende a ampliar a produção de álcool e açúcar, além de aumentar seus preços ${ }^{13}$.

Por fim, a Figura 9 apresenta as respostas das variáveis endógenas em relação a um impulso generalizado na taxa de câmbio. Observa-se uma consonância entre o comportamento das variáveis produção de açúcar (9.1) e exportação de açúcar (9.3). Logo, ambas possuem uma relação positiva de longo prazo e atingem, aproximadamente, no nono trimestre os maiores níveis de crescimento. Este fato corrobora com a dinâmica do setor e ressalta a importância do câmbio para um país exportador. No sentido contrário e de acordo com o esperado, a resposta da produção de álcool (9.2) é negativa a um impulso na taxa de câmbio devido à mesma motivar um detrimento da produção de álcool para suprir a oferta de açúcar. Já em relação à reposta do preço do álcool (9.7), observa-se um comportamento positivo no preço, que pode ser justificado pela redução da oferta de álcool. A resposta do câmbio (9.6) é positiva ao próprio impulso.

A resposta da variável preço recebido pelo produtor (9.4) é positiva devido ao aumento na demanda por matéria prima decorrente da expansão da oferta de açúcar. O preço do açúcar no varejo (9.5) também apresenta relação positiva a um impulso na taxa de câmbio. Esse resultado pode estar relacionado ao aumento na demanda do açúcar brasileiro decorrente de uma desvalorização cambial, que pode tornar os preços relativos mais baixos. O comportamento do preço da gasolina (9.8) é positivo até o quinto trimestre e oscila em patamares negativos nos semestres subsequentes. Tal resultado pode estar relacionado com o preço do álcool, porém o comportamento torna análise inconclusiva.

No geral, os resultados do modelo econométrico mostraram-se satisfatórios e, em parte, indicam o comportamento da dinâmica do setor. Dentre os diversos impulsos, um resultado teve resposta inconclusiva e cinco respostas, devido ao sentido Granger, não foram analisadas, visto que indicaram relação de causalidade.

13 As variáveis de produção de açúcar e álcool não foram analisadas, pois as mesmas, no sentido Granger, causam o preço da gasolina. Todavia, esse indício pode não ser coerente uma vez que a gasolina é influenciada por outros fatores. 


\section{CONSIDERAÇÕES FINAIS}

Neste estudo, analisou-se o impacto dos determinantes da oferta brasileira de açúcar e álcool no período de 1995 a 2009. Neste sentido, determinou-se a intensidade e a duração que as oscilações de preços e produções transmitem para o mercado e para a dinâmica do setor sucroalcooleiro brasileiro. As análises das funções impulso resposta em relação a um impulso nas exportações de açúcar mostraram, em geral, uma relação positiva com o preço recebido pelo produtor de cana e com a oferta de açúcar. Tal comportamento vai ao encontro do esperado e corrobora com a teoria de oferta agrícola. No sentido contrário, um impulso nas exportações de açúcar influencia negativamente no comportamento da produção de álcool.

Um impulso na produção brasileira de açúcar impactou positivamente na variável produção de álcool, ou seja, pode-se concluir que o aumento da produção de açúcar motiva, no mesmo sentido, o produtor em produzir álcool visto que ambos os produtos dependem da mesma matéria prima. Logo, a expansão de oferta de álcool, ocasionado por um choque na produção açucareira, reflete negativamente no comportamento preço do álcool. Já em relação ao comportamento do preço da gasolina, observa-se uma tendência negativa no curto prazo, seguida de oscilações positivas no longo prazo. O preço do açúcar no varejo apresentou resultado negativo ao longo dos períodos em relação a um impulso na produção de açúcar, fato este possivelmente provocado pela intensidade no choque da oferta. Já em relação ao comportamento do preço recebido do produtor de cana, o resultado foi incoerente, pois se esperava uma relação positiva.

No que tange ao choque na produção de álcool, pode-se concluir a dinâmica e o comportamento da oferta em relação a impulsos na produção pelo fato de que um choque na produção de álcool motiva, no mesmo sentido, a produção de açúcar. Logo, esse efeito gera uma resposta negativa nos preços do álcool e do açúcar no varejo. A resposta da variável exportação de açúcar e preço da gasolina apresentaram resultados negativos em relação a um choque na produção de álcool.

O impulso na variável preço recebido pelo produtor de cana em relação às respostas nas produções de açúcar e álcool indica uma relação de longo prazo positiva, justificando as análises anteriores. Adicionalmente, o comportamento positivo é observado nas variáveis de exportação de açúcar e preço do álcool. O preço da gasolina apresentou relação positiva no curto prazo, osci- lando negativamente nos períodos subsequentes.

A variável produção de álcool apresentou comportamento inverso a um choque no preço do açúcar. Em outras palavras, esse resultado pode estar indicando uma preferência do produtor em produzir açúcar devido ao impulso no preço do varejo.

Um impulso no preço do álcool impactou positivamente nas variáveis de exportação de açúcar e preço recebido pelo produtor de cana. Para a produção de açúcar, o efeito é negativo no curto prazo e positivo no longo prazo. Essa tendência pode estar relacionada diretamente com a decisão do produtor de cana de açúcar em oferta maior quantidade de ambos os produtos. A resposta da produção de álcool é negativa e pode ser justificada por uma possível elevação na demanda de mercado. $\mathrm{O}$ resultado do comportamento do preço da gasolina, em relação a esse impulso, pode estar relacionado com o aumento de preço do álcool, onde no curto prazo ocorra o efeito substituição por parte do consumidor.

As respostas em relação a um impulso no preço da gasolina apresentaram resultados positivos em todas as variáveis testadas, sendo que o preço do álcool teve maior impacto nos primeiros trimestres, indicando um possível aumento do consumo decorrente da elevação do preço da gasolina.

Nesse sentido, um choque na variável câmbio apresentou resultados coerentes e positivos em relação ao comportamento das variáveis produção de açúcar, exportação de açúcar, preço recebido pelo produtor de cana, preço do açúcar no varejo e preço do álcool. Porém, e de acordo com o esperado, a resposta da produção de álcool é negativa a um impulso no câmbio e, logo, conclui-se que as expansões da oferta de açúcar motivadas pelas variações cambiais podem ter causado uma queda na produção de álcool. Por fim, o comportamento da variável preço do álcool é positivo no curto prazo e oscila negativamente nos períodos subsequentes.

Conclui-se, então, que as inter-relações de preços e níveis de produções, analisadas no presente estudo, determinam de forma adequada o comportamento e a dinâmica da oferta de açúcar e do álcool brasileiro. Neste sentido, finaliza-se o presente artigo, recomendando-se novas pesquisas com a inclusão de novas variáveis e metodologias, que busquem captar a dinâmica da oferta do açúcar e do álcool brasileiro, possibilitando, assim, interpretações alternativas sobre o comportamento do setor sucroalcooleiro.

\section{REFERÊNCIAS}


ALBANEZ, T. et al. Uma análise da estrutura de custos do setor sucroalcooleiro. Custo e @gronegócio on line, Ribeirão Preto, 2008.

ALVES, J. A; LIMA, R. C. Transmissão de preços entre os mercados de açúcar espacialmente separados no Brasil: uma análise de co-integração. In: CONGRESSO BRASILEIRO DE ECONOMIA E SOCIOLOGIA RURAL, 48., 2010, Campo Grande (MS). Anais ... Piracicaba: SOBER, 2010.

ALVES, L. R. A. Transmissão de preços entre produtos do setor sucroalcooleiro do estado de São Paulo. 2002. 107p. Dissertação (Mestrado) - Escola Superior de Agricultura "Luiz de Queiroz", Universidade de São Paulo, Piracicaba, SP, 2002.

ALVES, Lucilio; BACCHI, M. R. P. Oferta de exportação de açúcar no Brasil. Rio de Janeiro: Editora, 2004. 25p. vol. 42.

BAER, Werner. A economia brasileira. 2 ed. São Paulo: Nobel, 2002. p. 33-34.

BANERJEE, A. et al. Co-integration, error-correction, and the econometric analysis of non stationary data (advanced texts in econometrics). New York: Oxford University Press inc, 1993.

BUENO, R. L. S. Econometria de séries temporais. $1^{a}$ Ed. São Paulo: Cengage Learning, 2008.

BITTENCOURT, G. M.; FONTES, R. M. O. Competitividade das exportações brasileiras de etanol. In: CONGRESSO BRASILEIRO DE ECONOMIA E SOCIOLOGIA RURAL, 48., 2010, Campo Grande (MS). Anais ... Piracicaba: SOBER, 2010.

CARUSO, R. C. Análise da oferta e demanda de açúcar no Estado de São Paulo. 2002. Dissertação (Mestrado) - Escola Superior de Agricultura, Universidade de São Paulo, Piracicaba, SP, 2002.

COLLA, C. et al. A relação marca, preço e consumo do açúcar: um estudo realizado em Cascavel/PR. In: CONGRESSO BRASILEIRO DE ECONOMIA E SOCIOLOGIA RURAL, 45., 2007, Londrina (PR). Anais ... Piracicaba: SOBER, 2007.

COSTA, M. L. O. Setor sucroalcooleiro: da rígida intervenção ao livre mercado. São Paulo: Método, 2003. p.69-189.

CUNHA, C. A. et al. Análise dos preços da cana- -de-açúcar sob regime shift. In: CONGRESSO BRASILEIRO DE ECONOMIA E SOCIOLOGIA RURAL, 46., 2008, Rio Branco (AC). Anais ... Piracicaba: SOBER, 2008.

FURTADO, Celso. Formação econômica do Brasil. São Paulo: Nacional, 2003. p.11-72.

FURTADO, Milton Braga. Síntese da economia brasileira. 7 ed. Rio de Janeiro: Livros Técnicos e Científicos Editora S.A, 2000. p. 22-35; 205-206.

MARJOTTA-MAISTRO, M. C. Ajustes nos mercados de álcool e gasolina no processo de desregulamentação. 2002. Tese (Doutorado) - Escola Superior de Agricultura "Luiz de Queiroz", Universidade de São Paulo, Piracicaba, SP, 2002.

MARTINS, A. P. et al. Análise da competitividade do açúcar brasileiro no mercado internacional, 1990 a 2004. In: CONGRESSO BRASILEIRO DE ECONOMIA E SOCIOLOGIA RURAL, 46., 2008, Rio Branco (AC). Anais ... Piracicaba: SOBER, 2008.

NOGUEIRA, P. R. de M. Longe do equilíbrio. Agroanalisys, São Paulo, v. 30, n. 3, p. 36-38, fev. 2011.

PRADO, JÚNIOR, C. História econômica do Brasil. 26 ed. São Paulo: Brasiliense, 1981. 354p.

SHIKIDA, P. F. A.; MARGARIDO, M. A. Uma análise econométrica da sazonalidade dos preços da cana-de-açúcar, no estado do Paraná, 2001-2007. Informações Econômicas, São Paulo, v. 39. p. 13, 2009.

SILVEIRA, A. M. A relação entre os preços de açúcar nos mercados doméstico e internacional. 2004. Dissertação (Mestrado) - Escola Superior de Agricultura "Luiz de Queiroz", Universidade de São Paulo, Piracicaba, SP, 2004.

SOUZA, A. N. Estudo das demandas de etanol e gasolina no Brasil no período 2001 a 2009. 2010. Dissertação (Mestrado) - Fundação Getúlio Vargas, Escola de Economia de São Paulo, São Paulo, SP, 2010.

SUZIGAN, Wilson. Indústria brasileira: origem e desenvolvimento. São Paulo: Hucitec, 2000. p. 213228.

TOMASETTO, M. Z. C. Transmissão de preços 
no mercado de cana-de-açúcar entre os estados de São Paulo e Paraná. 2010. Dissertação (Mestrado) - Universidade Estadual do Oeste do Paraná, PR, 2010.

TRICHES, D. et al. Análise do desempenho das exportações brasileiras de açúcar e as restrições da União Europeia. In: CONGRESSO BRASILEIRO DE ECONOMIA E SOCIOLOGIA RURAL, 48., 2010, Campo Grande (MS). Anais ... Piracicaba: SOBER, 2010.

UNIÃO DA INDÚSTRIA DE CANA DE AÇÚCAR (ÚNICA). Setor Sucroenergético / Dados e Cotações. 2010. Disponível em: <http://www.unica. com.br/>. Acesso em: 01 fev. 2012.
VERBEEK, Marno. A guide to modern econometrics. 3 ed. Rotterdam: RSM Erasmus University, 2008. p. 85-127; 171-195; 269-353.

VIAN, C. E. F. Agroindústria canavieira: estratégias competitivas e modernização. Campinas: Átomo, 2003. p. 7-49.

\section{APÊNDICE - Testes de Raíz Unitária}

Tabela A.1 Testes de raíz unitária

\begin{tabular}{|c|c|c|c|c|c|c|c|c|c|c|c|c|}
\hline \multirow[b]{2}{*}{ Série } & \multicolumn{6}{|c|}{ Augmented Dickey-Fuller (ADF) } & \multicolumn{6}{|c|}{ Augmented Dickey-Fuller (ADF) em diferença } \\
\hline & $\tau$ & p valor & $\tau_{\mu}$ & p valor & $\tau_{\tau}$ & p valor & $\tau$ & p valor & $\tau_{\mu}$ & p valor & $\boldsymbol{\tau}_{\tau}$ & p valor \\
\hline$s \_a c$ & 0.566 & 0.836 & -2.927 & 0.048 & -5.159 & 0.000 & -12.003 & 0.000 & -11.956 & 0.000 & -11.879 & 0.000 \\
\hline$s \_a l c$ & 0.091 & 0.708 & -3.772 & 0.005 & -3.876 & 0.019 & -12.091 & 0.000 & -11.985 & 0.000 & -11.876 & 0.000 \\
\hline$x \_a c$ & 1.019 & 0.917 & -0.951 & 0.765 & -4330 & 0.006 & -6.783 & 0.000 & -5.845 & 0.000 & $-5,774$ & 0.000 \\
\hline$p r \_c a n$ & 1.136 & 0.932 & -1.583 & 0.484 & -3.236 & 0.088 & -3.634 & 0.000 & -3.897 & 0.003 & -3.907 & 0.017 \\
\hline$p v \_a c$ & -1.324 & 0.169 & -1.055 & 0.727 & -3.311 & 0.074 & -5.227 & 0.000 & -5.318 & 0.000 & -5.322 & 0.003 \\
\hline$p \_a l c$ & 1.646 & 0.975 & -1.544 & 0.504 & -2.792 & 0.206 & -6.630 & 0.000 & -6.905 & 0.000 & -6.891 & 0.000 \\
\hline$p \_g a s$ & -3.743 & 0.999 & -2.498 & 0 & -0.589 & 76 & -5.618 & 0.000 & 41 & 0.000 & -7.503 & 0.000 \\
\hline \multirow[t]{2}{*}{ exc_r $r$} & -0.191 & 0.613 & -1.978 & 0.295 & -0.687 & 0.969 & -5.987 & 0.000 & -5.999 & 0.000 & -6.365 & 0.000 \\
\hline & \multicolumn{6}{|c|}{ Augmented Dickey-Fuller (ADF) } & \multicolumn{6}{|c|}{ Augmented Dickey-Fuller (ADF) em diferença } \\
\hline$s \_a c$ & 0.705 & 0.866 & -2.673 & 0.085 & -5.237 & 0.000 & -15.452 & 0.000 & -27.865 & 0.000 & -41.624 & 0.000 \\
\hline s_alc & 0.793 & 0.881 & 0.164 & 0.968 & -0.111 & 0.993 & -4.512 & 0.000 & -4.565 & 0.000 & -5.277 & 0.000 \\
\hline$x \_a c$ & 1.733 & 0.979 & -0.538 & 0.876 & -3.734 & 0.028 & -6.992 & 0.000 & -7.949 & 0.000 & -7.812 & 0.000 \\
\hline$p r \_c a n$ & -1.775 & 0.981 & -1.406 & 0.573 & -2.330 & 0.411 & -3.703 & 0.000 & -3.955 & 0.003 & -3.971 & 0.015 \\
\hline$p v \_a c$ & -0.785 & 0.372 & -0.704 & 0.847 & -2.224 & 0.479 & -5.162 & 0.000 & -5.138 & 0.000 & -5.130 & 0.000 \\
\hline$p i \_a c$ & 0.910 & 0.901 & -1.273 & 0.637 & -2.752 & 0.221 & -6.357 & 0.000 & -6.385 & 0.000 & -6.329 & 0.000 \\
\hline p_alc & 1.674 & 0.977 & -1.538 & 0.510 & -2.792 & 0.206 & -6.630 & 0.000 & -6.873 & 0.000 & -6.862 & 0.000 \\
\hline$p \_g a s$ & 3.222 & 0.999 & -2.498 & 0.121 & -0.589 & 0.976 & -5.806 & 0.000 & -6.892 & 0.000 & -7.503 & 0.000 \\
\hline exc_r & -0.191 & 0.613 & -1.953 & 0.306 & -0.621 & 0.974 & -5.966 & 0.000 & -5.904 & 0.000 & -6.252 & 0.000 \\
\hline
\end{tabular}

Nota: $\tau$ : sem intercepto; $\tau_{\mu}$ : intercepto; $\tau_{\tau}$ : tendência e intercepto. $\Delta$ denota que as variáveis são testadas em diferença. Todas as variáveis, quando testadas em nível, são I(1). Em diferença, elas se tornam I(0). 